combustion systems. He is the author or co-author of several published papers on combustion and heat transfer, and is the United Kingdom editor of the new review series, Progress in Combustion and Propulsion Science and Technology. Until recently he was a member of the Combustion and Propulsion Panel of the Advisory Group for Aeronautical Research and Development of NATO, in which capacity he con. tributed as author and editor to several publications of the Advisory Group for Aeronautical Research and Development.

Photography at the Federal Technical College, Zurich : Prof. W. F. Berg

DR. W. F. BERG has been appointed professor of the Photographic Institute of the Federal Technical College in Zurich, in succession to Prof. J. Eggert. Dr. Berg has already established an outstanding position as an authority on scientific aspects of photography. He started research work at the early age of sixteen in the X-ray laboratories of Siemens in Berlin under his father, Otto Berg, and graduated Dr. phil. of Berlin in 1932. The activities of the Nazis brought him to the University of Manchester in 1933, where he studied the growth of crystals, for which he was awarded a Ph.D. degree in 1936. In the same year he joined the Research Laboratories of Kodak, Ltd., where he soon began work on the fundamental processes in the formation of the photographic latent image. This work, on the temperature coefficient of sensitivity and the time required for build-up of the latent image, gave results in complete agreement with the theory of Gurney and Mott that the formation of the latest image was a two-stage process, and had much to do with the general acceptance of that theory. This work was followed by other investigations of the photographic process, less spectacular in their impact maybe, but not less important. This work was recognized by the award of a D.Sc. (Manchester) degree. For about a dozen years Dr. Berg has been in charge of aspects of research into photographic emulsions of more immediate practical application. His present appointment is a not unnatural result, not only of his authoritative position in photographic research work but also of his interest in education. He has been interested for many years in education in medical photography and is a member of the Education Committee of the Institute of British Photographers.

\section{Editor of Discovery: Mr. Gerald Leach}

Gerald Adrian Leach was recently appointed to the editorship of Discovery. Born in Colombo in 1933, Mr. Leach was educated at Glengorse School and Dauntsey's. He read for the Natural Sciences Tripos at Clare College, Cambridge, taking Part 1 in 1954, in physics, mathematics, geology and mineralogy, and Part 2 in 1955, in geology. Since Cambridge, he has been a full-time science writer and producer. In 1957 he worked on the Manchester Guardian as a general reporter and assistant to the Science Correspondent, and the following year was seript-writer for scientific documentary films with the Film Producers Guild. In 1959 he wrote and presented 35 programmes in the Associated Television science series, "It Can Happen To-morrow". In October that year he joined the BBC Television Outside Broadcasts Department as assistant producer on the 1960 "Eye on Research" television series. In 1960 and early this year he helped to plan, and write the scripts for, Dr. Bronowski's series, "Insight".
British Association for the Advancement of Science

ThE annual report for 1960-61 of the Council of the British Association to the General Committee characterizes the year as one of major expansion with a total audience of 140,000 , or nearly double that of any previous year, and a rapid growth in the demand for lectures and other forms of presentation of science (Pp. 31. London: British Association for the Advancement of Science, 1961). Three new Area Committees were established during the year, making a total of sixteen, and the Junior British Association meetings continued to expand, while an entirely new type of meeting was the science fair held in Manchester in March 1961. A grant of $£ 6,000$ from the Leverhulme Trust Fund enabled a research project for the study of the generating of mathematical insights to be initiated under Dr. Z. P. Dienes, and the work of the Unit is to last two years. During the year, films have been shown to audiences totalling 78,000 and other visual aids to audiences totalling 10,000. Some twelve receptions were organized, at which science teachers were shown a programme of films and other visual aids display. A survey of the use of visual aids by science teachers in schools in Essex was reported in The Advancement of Science for September 1960 and a more detailed report of the survey was in subsequent issues of the Film User. Following the Cardiff meeting, eight research committees were appointed on the recommendations of various sections and grants were made to three of these.

\section{Successful Operation of Nimrod Injector}

ON August 1 the first proton beam accelerated to the design energy of $15 \mathrm{MeV}$. was obtained from the linear-accelerator injector which forms the first stage of Nimrod, the 7,000-MeV. proton synchrotron under construction at the Rutherford High-Energy Laboratory of the National Institute for Research in Nuclear Science, Harwell. The linear accelerator consists of a cylindrical copper cavity approximately $44 \mathrm{ft}$. long and $5.5 \mathrm{ft}$. in diameter, with 48 drift tubes spaced along its axis, the whole being enclosed in a vacuum envelope. Approximately 1 MW. of radiofrequency power is supplied to the cavity at its resonant frequency of $115 \mathrm{Mc} / \mathrm{s}$. to set up the required accelerating fields across the gaps between drift tubes. The function of the drift tubes is to screen the protons from the field when its direction reverses every alternate half-cycle, and they also contain focusing magnets which constrain the protons to form a proper beam close to the machine axis. The drift tubes increase in length along the tank to correspond with the increase in proton velocity. Protons enter the linear accelerator with an initial energy of $0.6 \mathrm{MeV}$. from a pre-injection stage which is basically a conventional d.c. accelerator. Pulsed $15-\mathrm{MeV}$. beams will be delivered by the injector to the synchrotron at rates up to 2 per sec. and at pulse lengths up to $2 \mathrm{~m}$.sec. Within the synchrotron, they will be constrained to a circular path by a suitably varying magnetic field. In this way they will make many revolutions, receiving a small acceleration at a particular point in the orbit until the output energy of $7,000 \mathrm{MeV}$. is reached. Construction work on Nimrod started in August 1957 and is expected to be completed during 1962.

\section{Aeronautical Research in Asia and Africa}

THE International Civil Aviation Organization is to participate with the Governments of India, Morocco, 